\title{
Iklan, Citra Merek, Kualitas Pelayanan Terhadap \\ Kepuasan Konsumen dan Keputusan Pembelian
}

\author{
Putu Galih Jananuraga ${ }^{(1)}$ \\ Ni Putu Nina Eka Lestari ${ }^{(2)}$ \\ Universitas Pendidikan Nasional ${ }^{(1)}$ \\ Universitas Pendidikan Nasional ${ }^{(2)}$ \\ galihjananuraga121@gmail.com ${ }^{(1)}$ \\ ninajegeg@gmail.com ${ }^{(2)}$
}

\begin{abstract}
The purpose of this study was to analyze advertising, brand image, service quality on customer satisfaction and purchasing decisions. Data collection techniques using questionnaires with a sample of 100 respondents. This study uses SEM analysis techniques. The results of this study show, (1) the Ad variable to Consumer Satisfaction is a significant positive effect which has a standardized estimate (regression weight) of 0.298, (2) the Brand Image variable towards Consumer Satisfaction is a significant positive effect that has a standardized estimate (regression weight) amounting to 0.352, (3) Service Quality variables towards Consumer Satisfaction are significant positive influences which have standardized estimate (regression weight) of 0.224, (4) Advertising variables for Purchasing Decisions are not significant positive influences that have standardized estimate (regression weight) amounting to 0.093, (5) Brand Image variables on Purchasing Decisions is a significant positive effect that has a standardized estimate (regression weight) of 0.434, (6) Service Quality variables on Purchasing Decisions is a non-significant positive effect that has standardized esti mate (regression weight) of 0.112, (7) the Consumer Satisfaction variable on Purchasing Decisions is a significant positive effect which has a standardized estimate (regression weight) of 0.352 .

Keywords: Advertising; Brand Image; Service Quality; Consumer Satisfaction; Purchasing Decision
\end{abstract}


Tujuan penelitian ini adalah untuk menganalisis iklan, citra merek, kualitas pelayanan terhadap kepuasan konsumen dan keputusan pembelian. Teknik pengumpulan data menggunakan kuisioner dengan sampel sebanyak 100 responden. Penelitian ini menggunakan Teknik analisis SEM. Hasil penelitian ini menunjukan, (1) variabel Iklan terhadap Kepuasan Konsumen adalah berpengaruh positif yang signifikan yang memiliki standardized estimate (regression weight) sebesar 0,298, (2) variabel Citra Merek terhadap Kepuasan Konsumen adalah berpengaruh positif yang signifikan yang memiliki standardized estimate (regression weight) sebesar 0,352, (3) variabel Kualitas Pelayanan terhadap Kepuasan Konsumen adalah berpengaruh positif yang signifikan yang memiliki standardized estimate (regression weight) sebesar 0,224, (4) variabel Iklan terhadap Keputusan Pembelian adalah berpengaruh positif tidak signifikan yang memiliki standardized estimate (regression weight) sebesar 0,093, (5) variabel Citra Merek terhadap Keputusan Pembelian adalah berpengaruh positif yang signifikan yang memiliki standardized estimate (regression weight) sebesar 0,434 , (6) variabel Kualitas Pelayanan terhadap Keputusan Pembelian adalah berpengaruh positif tidak signifikan yang memiliki standardized estimate (regression weight) sebesar 0,112, (7) variabel Kepuasan Konsumen terhadap Keputusan Pembelian adalah berpengaruh positif yang signifikan yang memiliki standardized estimate (regression weight) sebesar 0,352.

\section{Kata Kunci: Iklan; Citra Merek; Kualitas Pelayanan; Kepuasan Konsumen; Keputusan Pembelian}




\section{PENDAHULUAN}

Semakin ketatnya persaingan di dunia bisnis, perusahaan harus mampu memberikan produk/jasa yang sesuai dengan kebutuhan dan keinginan kosumen. Tidak hanya memberikan produk yang sesuai dengan keinginan dan kebutuhan konsumen saja namun produk/jasa juga harus dirancang untuk memberikan solusi bagi masalah yang dihadapi oleh konsumen. Kondisi ini menuntut perusahaan untuk lebih inovatif dalam menawarkan produknya. Oleh karena itu perusahaan perlu memperhatikan variasi dan kualitas produk yang ditawarkan, harga yang sesuai dengan daya beli konsumen, lokasi penjualan dan yang terpenting bagaimana cara perusahaan menawarkan produk tersebut kepada konsumen. Untuk menarik perhatian konsumen, perusahaan harus dapat menciptakan strategi pemasaran yang efektif sehingga dapat menumbuhkan minat beli konsumen dan pada akhirnya konsumen puas dan akan memutuskan untuk membeli produk yang ditawarkan. Selain menarik minat konsumen untuk membeli produk, strategi pemasaran yang efektif dapat dijadikan sebagai salah satu cara untuk menghadapi persaingan dalam dunia bisnis. Strategi pemasaran adalah strategi untuk melayani pasar atau segmen pasar yang sedang ditargetkan oleh seorang pengusaha. Oleh karena itu, strategi pemasaran adalah kombinasi dari bauran pemasaran yang akan diterapkan oleh pengusaha untuk melayani pasar mereka. Pemasaran gabungan harus diatur sehingga akan dapat berfungsi sebagai senjata yang tepat sebagai perbandingan di pasar terhadap pesaing. Oleh karena itu, senjata harus disesuaikan dengan kondisi pasar dan kondisi persaingan di atasnya, jenis kombinasi pemasaran yang meliputi; produk, citra merek, harga, promosi, kualitas pelayanan, dan distribusi saluran (Nugraha et all, 2016; Ginantra et.al., 2017; Darma, 2019).

Dengan perkembangan teknologi yang sangat pesat dan melihat perilaku masyarakat modern yang bergantung dengan teknologi khususnya smartphone, radio, dan televisi perusahaan dapat memanfaatkan media tersebut untuk melakukan perencanaan startegi promosi dengan melalui iklan (Dewi dan Darma, 2019; Darma et.al., 2019). Menurut Kotler dan Amstrong (2012) iklan adalah segala bentuk penyajian dan promosi ide, barang atau jasa secara nonpersonal oleh suatu sponsor tertentu yang memerlukan pembayaran. Perusahaan tidak hanya membuat produk bagus tapi mereka juga harus menginformasikannya kepada konsumen mengenai kelebihan produknya dan dengan hati-hati memposisikan produknya dalam benak konsumen. Karena itu, mereka harus ahli dalam menggunakan promosi. Promosi 
ditujukan untuk mendapatkan pelanggan baru dan mempertahankan pelanggan yang ada. Fenomena yang terjadi di PT. Adiska Sarana Medika Kurangnya promosi dilihat dari cara perusahaan PT. Adiska Sarana Medika mempromosikan alat kesehatan (ortopedi) yang masih kurang, hal ini dikarenakan PT. Adiska Sarana Medika hanya menggunakan promosi dalam bentuk brosur. Disamping itu juga desain brosur nya yang kurang menarik membuat para konsumen tidak tertarik untuk melihat brosur yang di sebar. Dari masalah diatas bahwa faktor iklan sangat mempengaruhi minat beli konsumen. Menurut Setyo Ferry Wibowo \& Maya Puspita Karimah (2012) dan Aji Normawan Rosyid, Handoyo Djoko, Widayanto (2013) dimana dalam hasil penelitiannya iklan berpengaruh terhadap keputusan pembelian.

Selain iklan, faktor lain yang perlu diperhatikan untuk meningkatkan penjualan adalah citra merek. Dengan semakin terkenalnya sebuah merek, maka berdampak pada presepsi dan keyakinan dari konsumen atas produk tersebut sehingga dapat membentuk sebuah citra (Kanten dan Darma, 2017). Fadly (2014) Citra merek merupakan nilai utama pemasaran dan brand telah menjadi elemen krusial yang berkontribusi terhadap kesuksesan sebuah organisasi pemasaran. Citra terhadap merek berhubungan dengan sikap yang berupa keyakinan dan preferensi terhadap suatu merek. Konsumen yang memiliki citra yang positif terhadap suatu merek, akan lebih memungkinkan untuk melakukan pembelian (Setiadi, 2003; Farela dan Darma, 2014). Selain berbicara mengenai produk maka aspek yang perlu diperhatikan adalah kualitas produk. Fenomena yang terjadi di PT. Adiska Sarana Medika yaitu Selama ini PT. Adiska Sarana Medika menyediakan produk alat kesehatan (ortopedi) bermerek German dan sebagian bermerek China. Seperti yang diketahui merek German di masyarakat sudah dikenal, mempunyai nama dan kualitas yang bagus. Jadi untuk lebih menambah omset di PT. Adiska Sarana Medika perlu dilakukannya periklanan yg lebih menarik sehingga citra merek atau merk China bisa menambah tingkat penjualan di PT. Adiska Sarana Medika. Yesi Apriyani (2013) dan Mohamad H.P Wijaya (2013) menyatakan bahwa variabel Citra Merek terdapat pengaruh yang signifikan terhadap keputusan pembelian. Selain Iklan dan Citra Merek salah satu faktor yang terpenting adalah kualitas pelayanan, Tjiptono (2009) menyatakan, kualitas pelayanan (service quality) merupakan tingkat keunggulan yang diharapkan dan pengendalian atas tingkat keunggulan tersebut untuk memenuhi keinginan pelanggan. Fenomena yang terjadi di PT. Adiska Sarana Medika adalah dikatakan masih kurangnya dalam kualitas pelayanan. Karyawan di PT. Adiska Sarana Medika kurang memahami produk yang akan dipasarkan ke konsumen, 
sehingga mengakitbatkan konsumen masih mempertimbangkan dalam hal memilih produk yang di jual, maka dari itu kualitas pelayanan sangat berpengaruh terhadap keputusan pembelian suatu produk. Menurut Yesi Apriyani (2012) mengatakan kualitas pelayanan terhadap keputusan pembelian memiliki pengaruh yang positif. Arya Pradana (2009) menyatakan adanya pengaruh positif dan signifikan antara variabel kualitas pelayanan terhadap keputusan pembelian. M. Rizwar Ghazali (2010) mengatakan variabel kualitas pelayanan terhadap keputusan pembelian mempunyai pengaruh positif signifikan.

Kepuasan Konsumen adalah perasaan senang atau kecewa seseorang yang muncul setelah membandingkan kinerja (hasil) produk yang dipikirkan terhadap kinerja yang diharapkan. Philip Kotler dan Kevin Lane Keller (2007). Memuaskan kebutuhan konsumen adalah keinginan setiap perusahaan. Selain faktor penting bagi kelangsungan hidup perusahaan, memuaskan kebutuhan konsumen dapat meningkatkan keunggulan dalam persaingan. Konsumen yang puas terhadap produk dan jasa pelayanan cenderung untuk membeli kembali produk dan menggunakan kembali jasa pada saat kebutuhan yang sama muncul kembali dikemudian hari. Hal ini berarti kepuasan merupakan faktor kunci bagi konsumen dalam melakukan pembelian ulang yang merupakan porsi terbesar dari volume penjualan perusahaan. Selain faktor-faktor diatas yaitu iklan, citra merek, kualitas pelayanan, kepuasan konsumen, keputusan pembelian juga sangat penting untuk keberhasilan suatu perusahaan. Keputusan pembelian merupakan sikap seseorang untuk membeli atau menggunakan suatu produk baik berupa barang atau jasa yang telah diyakini akan memuaskan dirinya dan kesediaan menanggung resiko yang mungkin ditimbulkanya. Keputusan pembelian yang diambil oleh pembeli sebenarnya merupakan kumpulan dari sejumlah keputusan yang terorganisir (Aldi, 2012; Adnyana dan Darma, 2015).

Berdasarkan uraian diatas maka perlu diadakannya penelitian mengenai Iklan, Citra

\section{Merek, Kualitas Pelayanan Terhadap Kepuasan Konsumen dan Keputusan Pembelian.}

\section{Iklan}

Iklan adalah segala bentuk presentasi non-pribadi dan promosi gagasan, barang, atau jasa oleh sponsor tertentu yang harus dibayar (Kotler dan Keller, 2007). Bovee and Thill (2011) advertising is the delivery of announcements and promotional messages via time or space 
purchased in various media. McDaniel et al (2011) said that advertising is impersonal, oneway mass communication about a product or organization that is paid for by a marketer.

\section{Citra Merek}

Citra merek merupakan interprestasi akumulasi berbagai informasi yang diterima konsumen (Simamora \& Lim, 2002; Ginantra et.al., 2017). (Bilson Simamora, 2004) mendefinisikan citra merek sebagai seperangkat keyakinan, ide, dan kesan yang dimiliki oleh seseorang terhadap suatu merek, karena itu sikap dan tindakan konsumen terhadap suatu merek sangat ditentukan oleh citra merek tersebut.

\section{Kualitas Pelayanan}

Tjiptono (2009) menyatakan, service quality merupakan tingkat keunggulan yang diharapkan dan pengendalian atas tingkat keunggulan tersebut untuk memenuhi keinginan pelanggan. Tjiptono dan Chandra (2009) menyatakan, keunggulan layanan dapat dibentuk melalui pengintegrasian empat pilar service excellence yang saling berkaitan erat, yaitu: kecepatan, ketepatan, keramahan dan kenyamanan pelayanan.

\section{Kepuasan Konsumen}

Kepuasan konsumen adalah tingkat perasaan konsumen setelah membandingkan antara apa yang dia terima dan harapannya (Umar, 2005; Kanten dan Darma, 2017). Seorang pelanggan, jika merasa puas dengan nilai yang diberikan oleh produk atau jasa, sangat besar kemungkinannya menjadi pelanggan dalam waktu yang lama. Kepuasan Konsumen adalah perasaan senang atau kecewa seseorang yang muncul setelah membandingkan kinerja (hasil) produk yang dipikirkan terhadap kinerja yang diharapkan. (Kotler, 2007; Adnyana dan Darma, 2015).

\section{Keputusan Pembelian}

Keputusan pembelian merupakan sikap seseorang untuk membeli atau menggunakan suatu produk baik berupa barang atau jasa yang telah diyakini akan memuaskan dirinya dan kesediaan menanggung resiko yang mungkin ditimbulkanya. Keputusan pembelian yang diambil oleh pembeli sebenarnya merupakan kumpulan dari sejumlah keputusan yang 
terorganisir (Aldi: 2012). Junidah Alfianasari (2010), keputusan pembelian konsumen merupakan sikap konsumen dalam menentukan arah dan tujuan akhir dalam proses pembelian suatu produk.

\section{Kerangka Pemikiran}

Kerangka pemikiran merupakan model konseptual yang menggambarkan hubungan berbagai faktor sebagai permasalahan dalam penelitian ini. Berdasarkan uraian teori di atas dan penelitian terdahulu, kerangka pemikiran penelitian ini digambarkan melalui bagan berikut.

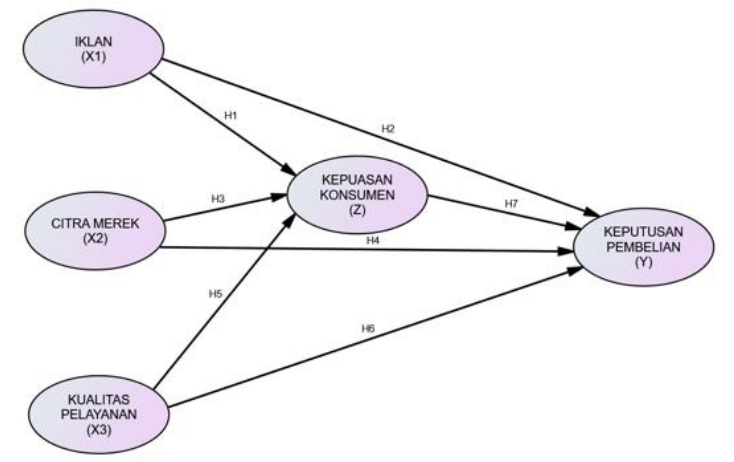

Gambar 1. Kerangka Pemikiran

\section{METODE PENELITIAN}

\section{Populasi dan Sampel}

Populasi adalah wilayah generalisasi yang terdiri atas obyek atau subyek yang mempunyai kualitas dan karakteristik tertentu yang ditetapkan oleh peneliti untuk dipelajari dan ditarik kesimpulannya (Sugiyono 2014). Populasi dalam penelitian ini diambil berdasarkan jumlah pembelian alat kesehatan (ortopedi) pada PT. Adiska Sarana Medika sebanyak 100 orang (10 rumah sakit yang ada di Denpasar) yang dimana 100 orang tersebut merupakan direktur, bagian penunjang, bagian pengadaan, bagian keuangan, kepala ruangan, bagian pelayanan, dokter dan 3 asisten dokter. Teknik pengambilan sampel menggunakan Teknik "sampel jenuh". Apabila populasi penelitian berjumlah kurang dari 100 maka sampel yang diambil adalah semuanya, namun apabila populasi penelitian berjumlah lebih dari 100 maka sampel dapat diambil antara $10-15 \%$ atau $20-25 \%$ atau lebih. Sugiyono (2014) menyatakan bahwa sampel jenuh adalah teknik penentuan sampel bila semua anggota populasi digunakan sebagai sampel. 


\section{Teknik Analisis Data}

Analisis data yang digunakan dalam penelitian ini adalah CB-SEM (Covariance BasedStructural Equation Modeling) dengan program AMOS (Analysis of Moment Structure). Menurut Ferdinand (2014), SEM merupakan gabungan dari dua metode statistik yang terpisah yaitu untuk mengkonfirmasi indikator - indikator dari sebuah variabel laten serta structural yang menggambarkan hubungan kausalitas antara dua atau lebih variabel.

\section{PEMBAHASAN}

\section{Uji Validitas}

\section{Tabel 1. Uji Validitas}

\begin{tabular}{|c|c|c|c|c|c|}
\hline No & Variabel & Indikator & $\begin{array}{c}\text { rhitung } \\
\text { (Corrected } \\
\text { Item-Total } \\
\text { Correlation) }\end{array}$ & rtabel & Keterangan \\
\hline \multirow{3}{*}{1} & \multirow{3}{*}{ Iklan } & iklan1 & 0,562 & 0,306 & $r_{\text {bitung }}>\mathrm{r}_{\text {tabel: }}$ Valid \\
\hline & & iklan2 & 0,746 & 0,306 & $r_{\text {bitung }}>\mathrm{r}_{\text {tabel: }}$ Valid \\
\hline & & iklan3 & 0,517 & 0,306 & rbitung $>$ rtabel: Valid \\
\hline \multirow{4}{*}{2} & \multirow{4}{*}{ Citra Merek } & citral & 0,741 & 0,306 & rbitung $>$ r tabel: Valid \\
\hline & & citra2 & 0,713 & 0,306 & rbitung $>$ rtabel: Valid \\
\hline & & citra3 & 0,870 . & 0,306 & $r_{\text {bitung }}>$ r tabel: $_{\text {falid }}$ \\
\hline & & citra4 & 0,811 & & Thitung $>$ Ttabel: Valid \\
\hline \multirow{5}{*}{3} & \multirow{5}{*}{$\begin{array}{l}\text { Kualitas } \\
\text { Pelayaanan }\end{array}$} & kual1 & 0,949 & 0,306 & rbitung $>$ rtabel: Valid \\
\hline & & kual2 & 0,961 & 0,306 & rbitung $>$ rtabel: Valid \\
\hline & & kual3 & 0,979 & 0,306 & roitung $>$ rtabel: Valid \\
\hline & & kual4 & 0,955 & 0,306 & rbitung $>$ r tabel: Valid \\
\hline & & kual5 & 0,961 & 0,306 & r bitung $>$ T tabel: Valid \\
\hline \multirow{3}{*}{4} & \multirow{3}{*}{$\begin{array}{l}\text { Kepuasan } \\
\text { Konsumen }\end{array}$} & puas1 & 0,774 & 0,306 & $r_{\text {bitung }}>r_{\text {tabel }}$ Valid \\
\hline & & puas2 & 0,888 & 0,306 & $r_{\text {hitung }}>$ rtabel: Valid \\
\hline & & puas3 & 0,657 & 0,306 & Dbitung $>$ Ttabel: Valid \\
\hline \multirow{4}{*}{5} & \multirow{4}{*}{$\begin{array}{l}\text { Keputusan } \\
\text { Pembelian }\end{array}$} & beli1 & 0,936 & 0,306 & rbitung $>$ rtabel: Valid \\
\hline & & beli2 & 0,972 & 0,306 & Thitung $>$ Tabel: Valid \\
\hline & & beli3 & 0,96 & 0,306 & rbitung $>$ rtabel $_{\text {Talid }}$ \\
\hline & & beli4 & 0,974 & 0,306 & Dohitung $>r_{\text {tabcl: }}$ Valid \\
\hline
\end{tabular}

Sumber: lampiran 4

Dari Tabel di atas dapat diketahui 19 indikator pertanyaan variabel iklan, citra merek, kualitas pelayanan, kepuasan konsumen dan keputusan pembelian adalah valid. Dengan demikian, 19 indikator pertanyaan variabel iklan, citra merek, kualitas pelayanan, kepuasan konsumen dan keputusan pembelian tersebut dapat digunakan untuk mengukur variabel iklan, citra merek, kualitas pelayanan, kepuasan konsumen dan keputusan pembelian. 


\section{Uji Reliabilitas}

Tabel 2. Uji Reliabilitas

\begin{tabular}{|c|l|c|c|}
\hline No & \multicolumn{1}{|c|}{ Variabel } & Cronbach's Alpha & N of Item \\
\hline 1 & Iklan & .765 & 3 \\
\hline 2 & Citra Merek & .888 & 4 \\
\hline 3 & Kualitas Pelayanan & .986 & 5 \\
\hline 4 & Kepuasan Konsumen & .874 & 3 \\
\hline 5 & Keputusan Pembelian & .973 & 4 \\
\hline
\end{tabular}

Sumber: lampiran 4

Dari tabel diatas ini berarti bahwa pertanyaan (kuesioner) variabel iklan, citra merek, kualitas pelayanan, kepuasan konsumen dan keputusan pembelian yang memiliki 19 pertanyaan adalah reliabel. Dengan demikian, daftar pertanyaan yang memiliki 19 pertanyaan variabel iklan, citra merek, kualitas pelayanan, kepuasan konsumen dan keputusan pembelian adalah reliabel untuk mengukur variabel iklan, citra merek, kualitas pelayanan, kepuasan konsumen dan keputusan pembelian. Artinya, dapat digunakan untuk mengukur variabel iklan, citra merek, kualitas pelayanan, kepuasan konsumen dan keputusan pembelian.

\section{Uji Normalitas}

Tabel 3. Uji Normalitas

\begin{tabular}{|c|l|c|l|l|l|l|l|}
\hline No & Variabel & \multicolumn{1}{|c|}{ Min } & \multicolumn{1}{|c|}{ Max } & \multicolumn{1}{c|}{ skew } & \multicolumn{1}{c|}{ c.r. } & Kurtosis & \multicolumn{1}{c|}{ c.r. } \\
\hline 1 & Iklan 1 & 3.000 & 10.000 & -.980 & -4.001 & 1.153 & 2.353 \\
& Iklan 2 & 4.000 & 10.000 & -1.208 & -4.933 & 1.353 & 2.763 \\
& Iklan 3 & 5.000 & 10.000 & -1.223 & -4.995 & 1.030 & 2.102 \\
\hline 2 & Citra 1 & 1.000 & 9.000 & -.308 & -2.341 & 1.375 & 2.849 \\
& Citra 2 & 2.000 & 9.000 & -.173 & -1.788 & 1.464 & 2.988 \\
& Citra 3 & 3.000 & 10.000 & -.333 & -2.811 & 1.403 & 2.867 \\
& Citra 4 & 3.000 & 10.000 & -.354 & -2.937 & 1.082 & 2.290 \\
\hline 3 & Kual1 & 2.000 & 10.000 & -.891 & -1.636 & .429 & 1.004 \\
& Kual2 & 1.000 & 10.000 & -1.059 & -2.325 & 1.225 & 2.114 \\
& Kual3 & 1.000 & 10.000 & -1.189 & -2.855 & 1.316 & 2.686 \\
& Kual4 & 1.000 & 10.000 & -1.171 & -2.783 & 1.289 & 2.631 \\
& Kual5 & 1.000 & 10.000 & -1.133 & -2.627 & 1.016 & 2.074 \\
\hline 4 & Puas3 & 5.000 & 10.000 & -.712 & -2.908 & .464 & .948 \\
& Puas2 & 5.000 & 10.000 & -.249 & -1.016 & -.159 & -.325 \\
& Puas1 & 5.000 & 10.000 & -.045 & -.182 & .103 & .211 \\
\hline 5 & Beli4 & 6.000 & 10.000 & -.373 & -1.522 & -.248 & -.507 \\
& Beli3 & 5.000 & 10.000 & -.524 & -2.139 & .647 & 1.320 \\
& Beli2 & 5.000 & 10.000 & -.360 & -1.468 & .672 & 1.373 \\
& Beli1 & 5.000 & 10.000 & -.138 & -.563 & .156 & .319 \\
\hline
\end{tabular}

Sumber: lampiran 5,6,7,8,9 (data diolah) 
Berdasarkan Tabel di atas dari 19 indikator variabel iklan, citra merek, kualitas pelayanan, kepuasan konsumen dan keputusan pembelian dapat diketahui bahwa tidak ada indikator yang memimiliki c.r untuk skweness lebih besar dari besar indikator masing-masing variabel memiliki c.r $\pm 3,00$. Ini berarti sebaran data untuk semua indikator iklan, citra merek, kualitas pelayanan, kepuasan konsumen dan keputusan pembelian adalah normal ditinjau dari kemencengan (skweness). Dilihat dari kurtosis (keruncingan), tidak ada indikator memiliki nilai c.r. > 3,00. Ini berarti, bila dilihat dari kurtosis (keruncingan) dapat dikatakan bahwa penyebaran data untuk semua indikator adalah normal.

Dengan terpenuhinya normalitas semua sebaran data untuk setiap variabel, maka uji parametrik berupa Analisis Confirmatory Faktor (CFA) dapat dilakukan.

\section{Analisis Faktor Confirmatory}

Tabel 4. Confirmatory Factor Analysis

\begin{tabular}{|c|c|c|c|c|c|c|c|c|}
\hline No & Variabel & & Unstandardized Estimate & Standardized Estimate & S.E. & C.R. & $P$ & Ket \\
\hline \multirow{3}{*}{1} & \multirow{3}{*}{ Iklan } & iklan3 <--- iklan & 1.000 & .832 & & & & Valid \\
\hline & & iklan2 <--- iklan & 1.277 & 1.010 & .093 & 12.683 & $* * *$ & Valid \\
\hline & & iklan1 <-- iklan & 1.239 & 1.239 & .102 & 12.098 & $* * *$ & Valid \\
\hline \multirow{4}{*}{2} & \multirow{4}{*}{ Citra Merek } & citra4 <--- citra & 1.000 & .794 & & & & Valid \\
\hline & & citra3 <--- citra & 1.193 & .860 & .130 & 9.173 & **** & Valid \\
\hline & & citra2 <--- citra & 1.197 & .741 & .157 & 7.634 & $* * *$ & Valid \\
\hline & & \begin{tabular}{|l|} 
citra1 <--- citra \\
\end{tabular} & 1.438 & .868 & .152 & 9.467 & $* * *$ & Valid \\
\hline \multirow{5}{*}{3} & \multirow{5}{*}{ Kualitas Pelayanan } & kual5 <--- kual & 1.000 & .925 & & & & Valid \\
\hline & & kual4 <-- kual & .993 & .948 & .053 & 18.649 & **** & Valid \\
\hline & & kual3<--- kual & 1.071 & .982 & .050 & 21.325 & **** & Valid \\
\hline & & \begin{tabular}{|l|} 
kual2 <-- kual \\
\end{tabular} & .948 & .940 & .053 & 17.760 & **** & Valid \\
\hline & & \begin{tabular}{|l|} 
kual1 --- kual \\
\end{tabular} & .941 & .890 & .064 & 14.814 & **** & Valid \\
\hline \multirow{3}{*}{4} & \multirow{3}{*}{ Kepuasan Konsumen } & puas $1<---$ puas & 1.000 & .797 & & & & Valid \\
\hline & & puas $2<--$ puas & 1.210 & 1.074 & .119 & 10.188 & $* * *$ & Valid \\
\hline & & puas $3<--$ puas & .740 & .681 & .091 & 8.123 & **** & Valid \\
\hline \multirow{4}{*}{5} & \multirow{4}{*}{ Keputusan Pembelian } & beli1 <-- beli & 1.000 & .889 & & & & Valid \\
\hline & & beli2 <--- beli & 1.065 & .970 & .064 & 16.746 & $* * *$ & Valid \\
\hline & & beli3 <--- beli & 1.109 & .950 & .070 & 15.824 & $* * *$ & Valid \\
\hline & & beli4 <--- beli & .866 & .803 & .080 & 10.779 & $* * *$ & Valid \\
\hline
\end{tabular}

sumber: lampiran 5,6,7,8,9 (data diolah)

Berdasarkan tampilan analisis faktor konfirmatori terhadap indikator variabel iklan, citra merek, kualitas pelayanan, kepuasan konsumen dan keputusan pembelian baik dalam bentuk diagram maupun dalam bentuk tabel diatas, diketahui bahwa Standardized Regression Weight $(\lambda)$ untuk semua indikator iklan, citra merek, kualitas pelayanan, kepuasan konsumen dan keputusan pembelian adalah lebih besar dari 0,50 dan C.R. lebih besar dari 2,00 serta nilai probabilitas ke-19 indikator tersebut lebih kecil dari 0,05 (***). Dengan demikian dapat dikatakan ditinjau dari CFA, bahwa ke-19 indikator tersebut valid sebagai indikator yang 
membentuk variabel laten iklan, citra merek, kualitas pelayanan, kepuasan konsumen dan keputusan pembelian.

Dari hasil analisis normalitas dan CFA untuk setiap variabel laten di atas, maka dapat diketahui bahwa semua dari indikator variabel layak untuk diikutkan pada analisis lanjut.

\section{Analisis pengaruh dengan SEM}

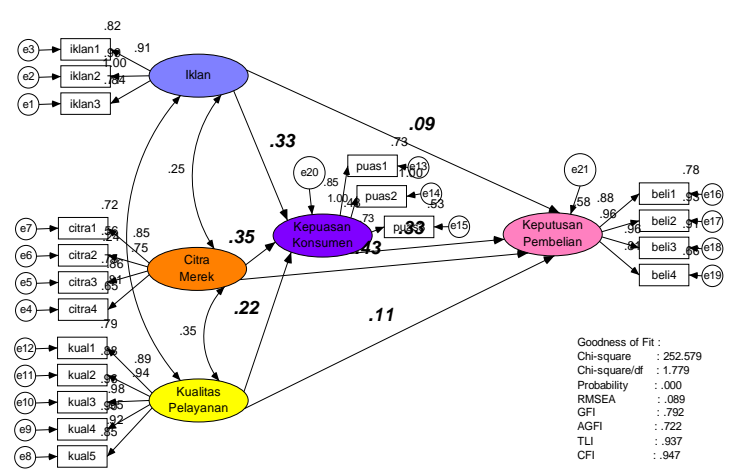

Gambar 2. Analisis SEM

Sumber: lampiran 11

Berdasarkan gambar di atas dapat dilakukan analisis Goodness of fit, analisis model struktural, analisis determinasi, analisis model pengukuran dengan parameter lamda untuk pengaruh Iklan, Citra Merek, Kualitas Pelayanan Terhadap Kepuasan Konsumen Dan Keputusan Pembelian Alat Kesehatan (Ortopedi) Pada PT. Adiska Sarana Medika.

\section{Analisis Pengujian Model Pengukuran dengan Parameter Lamda $(\lambda i)$}

Tabel 5. Regression Weight (Lamda) Indikator Iklan, Citra Merek, Kualitas Pelayanan, Kepuasan Konsumen Dan Keputusan Pembelian

\begin{tabular}{|c|c|c|c|c|c|c|c|c|}
\hline & & & 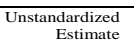 & $\begin{array}{r}\text { Standardized } \\
\text { Estimate }\end{array}$ & S.E. & C.R. & $P$ & Ket \\
\hline iklan3 & $<--$ & Iklan & 1.000 & .843 & & & & Valid \\
\hline iklan2 & $<--$ & Iklan & 1.245 & .997 & .087 & 14.387 & $* * *$ & Valid \\
\hline iklan1 & $<--$ & Iklan & 1.239 & .907 & .099 & 12.570 & $* * *$ & Valid \\
\hline citra4 & $<--$ & citra & 1.000 & .806 & & & & Valid \\
\hline citra3 & $<--$ & citra & 1.179 & .863 & .124 & 9.507 & $* * *$ & Valid \\
\hline citra2 & $<--$ & citra & 1.185 & . 745 & 151 & 7.844 & $* * *$ & Valid \\
\hline citra1 & $<--$ & citra & 1.388 & .851 & .145 & 9.567 & $* * *$ & Valid \\
\hline kual5 & $<--$ & kual & 1.000 & .924 & & & & Valid \\
\hline kual4 & $<--$ & kual & .993 & .948 & .053 & 18.583 & $* * *$ & Valid \\
\hline kual3 & $<--$ & kual & 1.071 & .981 & .050 & 21.266 & $* * *$ & Valid \\
\hline kual2 & $<--$ & kual & 949 & .941 & .053 & 17.789 & $* * *$ & Valid \\
\hline kual1 & $<--$ & kual & .943 & .891 & .063 & 14.867 & $* * *$ & Valid \\
\hline beli1 1 & $<--$ & beli & 1.000 & .885 & & & & Valid \\
\hline beli2 & $<--$ & beli & 1.063 & .964 & .065 & 16.309 & $* * *$ & Valid \\
\hline beli3 & $<--$ & beli & 1.121 & .956 & .071 & 15.818 & $* * *$ & Valid \\
\hline beli4 & $<--$ & beli & .879 & .812 & .081 & 10.901 & $* *$ & Valid \\
\hline puas1 & $<--$ & puas & 1.000 & .855 & & & & Valid \\
\hline puas2 & $<--$ & puas & 1.052 & 1.002 & .072 & 14.586 & $* * *$ & Valid \\
\hline puas3 & $<--$ & puas & .740 & .730 & .083 & 8.929 & $* * *$ & Valid \\
\hline
\end{tabular}

Sumber: lampiran 11 
Dari tabel di atas dapat dilihat bahwa semua indikator variabel latent memiliki standardized estimate (regression weight) berupa loading factor atau lamda $(\lambda i)>0,50$, nilai kritis C.R > 2,00 serta memiliki probabilitas lebih kecil dari 0,05 (***). Dengan demikian dapat dikatakan bahwa semua loading factor atau lamda $(\lambda \mathrm{i})$ indikator tersebut adalah valid/signifikan.

\section{Analisis Goodness of Fit}

Tabel 6. Evaluasi Goodness of Fit

\begin{tabular}{|c|c|c|c|}
\hline Goodness of Fit Index & $\begin{array}{l}\text { Cut-of } \\
\text { Value }\end{array}$ & $\begin{array}{c}\text { Hasil } \\
\text { Model }\end{array}$ & Keterangan \\
\hline Chi-square $\left(x^{2}\right)$ & $\begin{array}{c}\text { Diharapkan } \\
\text { kecil }\end{array}$ & 252,579 & Kurang baik \\
\hline $\begin{array}{l}\text { Relatitive Chi-square } \\
\left(x^{2} / \mathrm{df}\right)\end{array}$ & $\leq 3,00$ & $\left.1,779^{\circ}\right)$ & Baik \\
\hline Probability & $>0,05$ & 0,000 & Kurang baik \\
\hline RMSEA & $\leq 0,08$ & (0,089") & Baik \\
\hline GFI & $\geq 0,90$ & 0,792 & Kurang baik \\
\hline AGFI & $\geq 0,90$ & 0,722 & Kurang baik \\
\hline TLI & $\geq 0,95$ & $\left.0,937^{\cdots}\right)$ & Marginal \\
\hline CFI & $>0,95$ & $\left.0,947^{* *}\right)$ & Marginal \\
\hline
\end{tabular}

**) Marginal

Memperhatikan nilai cut-of-value dan goodness of fit hasil model pada Tabel 4.27 di atas, terlihat dua kriteria yang terpenuhi dan dari delapan kriteria yang dipakai. Kriteria yang terpenuhi adalah Relatitive Chi-square ( $\left.\chi^{2} / \mathrm{df}\right)$ dan RMSEA, serta yang marginal TLI dan CFI, sisanya kurang baik adalah Chi-square $\left(\chi^{2}\right)$, Probability, GFI dan AGFI. Karena sudah dua kriteria terpenuhi dan dua marginal dari delapan kriteria yang disyaratkan, maka model di atas dapat dinyatakan sebagai model yang baik dipandang tidak perlu diadakan modifikasi model sesuai dengan pendapat yang dikemukakan oleh (Solimun, 2002 dan Solimun, 2004)

\section{Analisis Model Pengukuran dengan Determinasi}

Tabel 7. Squared Multiple Correlations:

(Group number 1 - Default model)

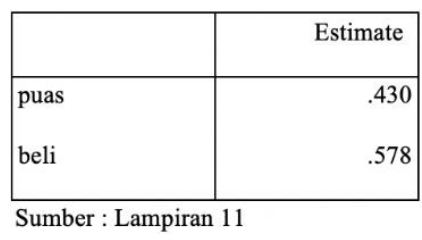

Square Multiple Correlation yang nilainya masing-masing sebesar 0,430 dan 0,578 sebagaimana terlihat pada Tabel 4.30 di atas. Menurut Ferdinand, 2002 nilai Square Multiple 
Correlation untuk variabel kepuasan konsumen (puas) dan dan keputusan pembelian (beli) identik dengan R2 pada SPSS sebesar 0,430 dan 0,578, maka besarnya Determinasi adalah nilai Square Multiple Correlation untuk variabel iklan, citra merek dan kualitas pelayanan kali $100 \%=0,430 \times 100 \%=43,0 \%$. Dengan demikian dapat dinyatakan bahwa perubahan kepuasan konsumen dipengaruhi oleh iklan (X1), citra merek (X2) dan kualitas pelayanan (X3) sebesar 43,0\%. Sedangkan nilai Square Multiple Correlation untuk variabel iklan, citra merek, kualitas pelayanan dan kepuasan konsumen kali $100 \%=0,578 \times 100 \%=57,8 \%$. Dengan demikian dapat dinyatakan bahwa perubahan kepuasan konsumen dipengaruhi oleh iklan (X1), citra merek (X2), kualitas pelayanan (X3) dan kepuasan konsumen (Z) sebesar $57,8 \%$.

\section{PENUTUP}

Berdasarkan dari hasil penelitian yang dilakukan di PT. Adiska Sarana Medika dan hasil pembahasan diatas, maka dapat disimpulkan bahwa pengaruh variabel iklan terhadap Kepuasan Konsumen memiliki standardized estimate (regression weight) sebesar 0,328, dengan $\mathrm{Cr}$ (Critical ratio = identik dengan nilai t-hitung) sebesar 3,781 pada probability ***. Nilai CR 3,781 $>$ 2,000 dan Probability $=* * *<0,05$ menunjukkan bahwa pengaruh variabel Iklan terhadap Kepuasan Konsumen adalah berpengaruh positif yang signifikan. Pengaruh variabel Citra Merek terhadap Kepuasan Konsumen memiliki standardized estimate (regression weight) sebesar 0,325, dengan $\mathrm{Cr}$ (Critical ratio = identik dengan nilai t-hitung) sebesar 3,620 pada probability $* * *$. Nilai CR 3,620 $>2,000$ dan Probability $=* * *<0,05$ menunjukkan bahwa pengaruh variabel Citra Merek terhadap Kepuasan Konsumen adalah berpengaruh positif yang signifikan. Pengaruh variabel Kualitas Pelayanan terhadap Kepuasan Konsumen memiliki standardized estimate (regression weight) sebesar 0,224, dengan $\mathrm{Cr}$ (Critical ratio $=$ identik dengan nilai t-hitung) sebesar 2,596 pada probability 0,009 . Nilai CR 2,596 2,000 dan Probability = 0,009 $<0,05$ menunjukkan bahwa pengaruh variabel Kualitas Pelayanan terhadap Kepuasan Konsumen adalah berpengaruh positif yang signifikan. Pengaruh variabel iklan terhadap Keputusan Pembelian memiliki standardized estimate (regression weight) sebesar 0,093, dengan $\mathrm{Cr}$ (Critical ratio = identik dengan nilai t-hitung) sebesar 1,141 pada probability 0,254. Nilai CR 1,141 <2,000 dan Probability = 0,254 > 0,05 menunjukkan bahwa pengaruh variabel Iklan terhadap Keputusan Pembelian adalah 
berpengaruh positif tidak signifikan. Pengaruh variabel Citra Merek terhadap Keputusan Pembelian memiliki standardized estimate (regression weight) sebesar 0,434, dengan $\mathrm{Cr}$ (Critical ratio $=$ identik dengan nilai t-hitung) sebesar 4,412 pada probability ***. Nilai CR 4,412 > 2,000 dan Probability $=* * *<0,05$ menunjukkan bahwa pengaruh variabel Citra Merek terhadap Keputusan Pembelian adalah berpengaruh positif yang signifikan. Pengaruh variabel Kualitas Pelayanan terhadap Keputusan Pembelian memiliki standardized estimate (regression weight) sebesar 0,112, dengan $\mathrm{Cr}$ (Critical ratio = identik dengan nilai t-hitung) sebesar 1,398 pada probability 0,162 . Nilai CR $1,398<2,000$ dan Probability $=0,162>0,05$ menunjukkan bahwa pengaruh variabel Kualitas Pelayanan terhadap Keputusan Pembelian adalah berpengaruh positif tidak signifikan. Pengaruh variabel Kepuasan Konsumen terhadap Keputusan Pembelian memiliki standardized estimate (regression weight) sebesar 0,325, dengan $\mathrm{Cr}$ (Critical ratio = identik dengan nilai t-hitung) sebesar 3,153 pada probability 0,002. Nilai CR 3,153 > 2,000 dan Probability $=0,002<0,05$ menunjukkan bahwa pengaruh variabel Kepuasan Konsumen terhadap Keputusan Pembelian adalah berpengaruh positif yang signifikan.

Berdasarkan hasil penelitian tersebut maka peneliti dapat memberikan beberapa saran. Adapun saran yang dapat disampaikan oleh peneliti adalah sebagai berikut. Variabel iklan, citra merek dan kualitas pelayanan meningkatkan kepuasan konsumen, maka disarankan kepada pimpinan PT. Adiska Sarana Medika agar tetap melaksanakan atau bila perlu lebih ditingkatkan pelaksanaan kebijakan yang berkaitan dengan iklan, citra merek dan kualitas pelayanan untuk menjaga dan meningkatkan kepuasan konsumen.Variabel citra merek dan kualitas pelayanan meningkatkan keputusan pembelian, maka disarankan kepada pimpinan PT. Adiska Sarana Medika agar tetap melaksanakan atau bila perlu lebih ditingkatkan pelaksanaan kebijakan yang berkaitan dengan citra merek dan kualitas pelayanan untuk meningkatkan keputusan pembelian alat kesehatan (ortopedi) dari konsumen.Variabel citra merek paling dominan mempengaruhi kepuasan konsumen PT. Adiska Sarana Medika, maka disarankan kepada pimpinan pada PT. Adiska Sarana Medika agar manajemen atau pimpinan PT. Adiska Sarana Medika lebih banyak memperhatikan dan melaksanakan faktor-faktor citra merek kemudian disusul iklan dan kualitas pelayanan. Sedangkan variabel citra merek paling dominan mempengaruhi keputusan pembelian alat kesehatan (ortopedi) pada PT. Adiska Sarana Medika agar manajemen atau pimpinan PT. Adiska Sarana Medika lebih banyak memperhatikan dan melaksanakan faktor- 
faktor citra merek kemudian disusul kepuasan konsumen. Hasil penelitian ini hendaknya dapat dipergunakan sebagai bahan untuk penelitian bagi mahasiswa berikutnya dengan mempertimbangkan keterbatasan-keterbatasan dalam penelitian ini. Bagi penelitian selanjutnya disarankan agar dalam penelitiannya menggunakan variabel lain diluar variabel bebas yang digunakan dalam penelitian ini ataupun mengkombinasi variabel di dalam penelitian ini dalam variabel lain di luar variabel penelitian ini. 


\section{DAFTAR PUSTAKA}

Adnyana, R., and Darma, G.S. (2015). Strategi Marketing Mix, Yield Management, Customer Satisfaction and Occupancy Rate, Jurnal Manajemen \& Bisnis, 12 (1): 92-115.

Aldi, A. (2012). Pengaruh Citra Merk dan Kualitas Produk Terhadap Keputusan Pembelian Konsumen. Yogyakarta: Universitas Negeri Yogyakarta.

Alfianasari, J. (2010). Pengaruh Komunikasi Pemasaran Terhadap Keputusan Pembelian Kartu Perdana IM3, Skripsi Fakultas Ekonomi Universitas Hasanuddin.

Darma, G.S. (2019). Kacamata Media, Kesuksesan Bersyarat. Indonesia: Pustaka Larasan Press.

Darma, G.S., Apollo, A., Rusmanda, G., and Umar, Y. (2019). Digital Education 4.0. Indonesia: Cakra Media Utama Press.

Dewi, M.V.K., and Darma, G.S. (2019). The Role of Marketing \& Competitive Intelligence In Industrial Revolution 4.0, Jurnal Manajemen \& Bisnis, 16 (1): 1-12.

Fadly. (2014). Pengaruh Retailing Mix Terhadap Keputusan Pembelian Konsumen (Studi Kasus Pada Minimarket Eramart di Kota Samarinda), Jurnal Administrasi, 2.

Farela, D., and Darma, G.S. (2014). Celebrity Endorser, Daya Tarik Iklan, Brand Awareness dan Brand Attitude, Jurnal Manajemen \& Bisnis, 11 (1): 35-47.

Ferdinand. (2002). Metode Penelitian Manajemen: Pedoman Penelitian Untuk Skripsi, Tesis, Dan Desertasi Ilmu Manajemen. Semarang: Badan Penerbit Universitas Diponegoro

Ferdinand, A. (2014). Structural Equation Modeling, Edisi 5. Semarang: Badan Penerbit Universitas Diponegoro.

Ginantra, K.G., Lestari, N.P.N.E., Gorda, A.A.N.E.S., and Darma, G.S. (2017). Effects of Promotion, Product Quality, Brand Image and Price on Customer Satisfaction and Brand Switching Decision, International Journal of Management and Economics Invention, $\mathbf{3}$ (12): 1514-1523.

Kanten, I.K., and Darma, G.S. (2017). Consumer Behaviour, Marketing Strategy, Customer Satisfaction, and Business Performance, Jurnal Manajemen \& Bisnis, 14 (2): 143-165.

Kotler, P., and Amstrong, G. (2012). Principles of Marketing. New Jersey: Pearson Education Limited.

Kotler, P., dan Keller, K.L. (2007). Manajemen Pemasaran. Jakarta: Indeks. 
Kodu, S. (2013). Harga, Kualitas Produk dan Kualitas Pelayanan Pengaruhnya Terhadap Keputusan Pembelian Mobil Toyota Avanza, Jurnal EMBA 1251, 1 (3): 1251-1259.

Nugraha, I.M.A.E., Lestari, N.P.N.E., Arjawa, I.G.W. (2016). Competitive Market Strategy of Traditional Merchandise Market against Modern Merchandise Market in Bali, Indonesia, International Journal of Management and Commerce Innovations, 3 (2): 663-671.

Rosyid, A.N., Widayanto, H.D. (2013). Pengaruh Kualitas Produk, Citra Merek, Harga dan Iklan Terhadap Keputusan Pembelian Sepeda Motor Honda Revo (Studi Kasus pada Konsumen Sepeda Motor Honda Revo Astra Motor Kebumen), Diponegoro Journal of Social and Politic: $1-8$.

Setiadi, N.J. (2013). Perilaku Konsumen: Perspektif Kontemporer pada Motif, Tujuan dan Keinginan Konsumen. Jakarta: Kencana.

Simamora, B., dan Lim, J. (2002). Aura Merek: 7 Langkah Membangun Merek yang Kuat. Jakarta: Gramedia Pustaka Utama.

Solimun. (2002). Multivariate Analysis Structural Equation Modelling (SEM) Lisrel dan Amos. Fakultas MIPA.

Solimun. (2008). Memahami Metode Kuantitatif Mutakhir: Structural Equation Modeling \& Partial Least Square, Program Studi Statistika FMIPA Universitas Brawijaya Sugiyono. (2014). Metode Penelitian Pendidikan Pendekatan Kuantitatif, Kualitatif, dan R\&D. Bandung: Alfabeta.

Tjiptono, F. (2009). Service Marketing: Esensi \& Aplikasi. Yogyakarta: Marknesis.

Umar, H. (2005). Manajemen Riset dan Perilaku Konsumen. Jakarta: PT. Gramedia Pusat. Wibowo, S.F., \& Karimah, M.P. (2012). Pengaruh Iklan Televisi Dan Harga Terhadap Keputusan Pembelian Sabun Lux (Survei Pada Pengunjung Mega Bekasi Hypermall), Jurnal Riset Manajemen Sains Indonesia (JRMSI), 3 (1).

Wijaya, M.H.P. (2013). Promosi, Citra Merek, Dan Saluran Distribusi Pengaruhnya Terhadap Keputusan Pembelian Jasa Terminix Di Kota Manado, Jurnal EMBA, 1 (4): 105-114.

Weenas, J.R.S. (2013). Kualitas Produk, Harga, Promosi Dan Kualitas Pelayanan Pengaruhnya Terhadap Keputusan Pembelian Spring Bed Comforta, Jurnal EMBA, 1 (4): 607-618.

Yesi, A. (2013). Pengaruh Brand Image, Harga Dan Kualitas Pelayanan Terhadap Keputusan Pembelian Ulang Pizza Hut di Kota Padang. 